\title{
A Research on Effect of Sewage Sludge Ash on the Mechanical Properties of Composite Material
}

\author{
M. Akif Kutuk, Z. Abidin Oguz \\ University of Gaziantep \\ Mechanical Engineering Department, Gaziantep, Turkiye \\ kutuk@gantep.edu.tr, oguzeynal02@hotmail.com
}

\begin{abstract}
In the current study, effect of sewage sludge ash on the mechanical properties of particle filled composite material is investigated experimentally. The weight rate of sewage sludge ash which would be applied tensile test, three point bending test, and impact test is changing between $0 \%$ and $45 \%$ of overall mixture. Tests are made in mechanics laboratory and for tensile test and three point bending test, the speed of test machine is adjusted as $1 \mathrm{~mm} / \mathrm{min}$ and $2 \mathrm{~mm} / \mathrm{min}$ respectively. According to the result of three point bending test, maximum stress tends to decrease with increased rate of sewage sludge ash in the composite. According to the result of tensile test, maximum stress tends to increase with the sewage sludge ash particles content up to $20 \%$ ratio of overall mixture and beyond that ratio it tends to decrease. According to result of impact test; impact resistance increase until weight rate of ash reaches 10 $\%$. The impact resistance decrease between the weight rate of ash $10 \%$ and $25 \%$ and then impact resistance remains constant until rate of ash reach $40 \%$.
\end{abstract}

Keywords: Sewage sludge ash, tensile test, three point bending test, impact test, particle filled composite

\section{Introduction}

Composite materials ; can not be solved in each of two or more materials are suitable properties in a single material or gather material obtained as a result of combining the macro or micro level in order to create a new property. Composite materials because of low weight and high strength that enables automotive, construction, marine and aerospace vehicles are preferred [1]. Physical and mechanical characteristics can be changed with a solid additives added during the preparation of the composite matrix [2]. Particulate polymer composites (PPCs) generally consist of micro - or nano - fillers of different sizes and shapes randomly dispersed in polymer matrices. Over the years there has been considerable interest in these materials since the dispersed fillers can be used to easily control the overall stiffness, strength, fracture toughness and impact energy absorption of the resulting composite [3]. PATNAIK at al. [4] studied a series of glass fiber reinforced polyester composites are fabricated using flyash, aluminum oxide $\left(\mathrm{Al}_{2} \mathrm{O}_{3}\right)$ and silicon carbide (SiC) particles as filler materials. The effects of these three different ceramics on the mechanical properties of glass-polyester composites are investigated. It has been found that the incorporation of these fillers, the tensile strength of the composites decrease significantly. The flexural properties, interlaminar shear strength, density and hardness are also affected by the type and content of filler particles. It is found that the presence of $\mathrm{SiC}$ improves the hardness of the glass-polyester composites, whereas the other two fillers show marginal effect. The study reveals that the reduction in tensile strength is the minimum in case of fly ash among all the fillers. Further, the composite with low fly ash content (10 wt \%) exhibits improved flexural strength. It is thus interesting to find that an industrial waste - like fly ash shows better filler characteristics compared to those of alumina and SiC. Moreover, being cheap and easily available, it would hopefully provide a cost effective solution to composite manufacturers. RAJU at al. [5] studied the mechanical and two-body abrasive wear behaviour of alumina $\left(\mathrm{Al}_{2} \mathrm{O}_{3}\right)$ filled glass fabric reinforced epoxy $(\mathrm{G}-\mathrm{E})$ composites. From the experimental investigation, it was found that the presence of $\mathrm{Al}_{2} \mathrm{O}_{3}$ filler improved the tensile strength and tensile modulus of the G-E composite. Inclusion of $\mathrm{Al}_{2} \mathrm{O}_{3}$ filler reduced the specific wear rate of G-E composite. The results show that in abrasion mode, as the filler loading increases the wear volume decreases and increased with increasing abrading distance. The excellent wear resistance was obtained for $\mathrm{Al}_{2} \mathrm{O}_{3}$ filled G-E composites. Furthermore, $10 \mathrm{wt} \%$ filler loading gave a very less wear loss. RUSU at al. [6] investigated 
the mechanical and thermal proporties of HDPE/zinc powder composites. According to their study, the composites present poorer mechanical properties as compared to the unfilled polymer. The density and hardness of HDPE/zinc composites are higher than that for the unfilled polymer. The thermal stability of the HDPE charged with zinc powder is better that for the unfilled polymer. The incorporation of zinc powder in HDPE increases the thermal diffusivity and conductivity and decreases the specific heat. GÜNGÖR [7] investigated the mechanical properties of high density polyethylene (HDPE) and HDPE containing Fe polymer composites experimentally. As compared to the mechanical properties of unfilled HDPE, Fe filled polymer composites showed lower yield and tensile strength, \% elongation, and Izod impact strength, while the modulus of elasticity and hardness of the composites were higher than those of HDPE. Addition of 5 vol. $\%$ Fe reduced Izod impact strength and \% elongation of HDPE about $40 \%$ and $90 \%$ respectively and increased the modulus of elasticity of HDPE about $31 \%$. BGAGYASHEKAR at al.[8]studied on RT cure epoxy composite system comprised of metallic and non-metallic fillers. The results of the studies carried out on composites with three distinctly different particulate fillers, representing ductile $(\mathrm{Cu}$ and $\mathrm{Al})$, brittle $(\mathrm{SiC})$, and soft $(\mathrm{Gr})$ type of materials regarding the mechanical properties, showed that the tensile and flexural strength of the particulate composites degraded with filler loading, whereas the modulus (both tensile andflexural) of the composites increased with the filler loading for the range of filler contents considered (10-40 $\mathrm{wt} \%)$.

Although researches were already accomplished investigating the use of sewage sludge ash for the building materials manufacturing, such as produce bricks and tiles, as a raw materials for cement production, as aggregates for concrete and mortar, as a component of the synthesis of lightweight materials and as substitute for sand and/or cement in cement stabilized bases, subbases and embankments in road constuctions [19, 20, 21], SSA didn't used in polymer comosite material.

In the literature, there can be seen that most material has been used either self state (Al,Cu,etc.) or has been used with compound state $\left(\mathrm{SiC}, \mathrm{Al}_{2} \mathrm{O}_{3}\right)$ as additive for composite materials. In this study,apart from literature sewage sludge ash that contains $\mathrm{Al}_{2} \mathrm{O}_{3}, \mathrm{BaO}, \mathrm{Br}, \mathrm{CaO}, \mathrm{Cl}, \mathrm{Cr}_{2} \mathrm{O}_{3}, \mathrm{CuO}, \mathrm{Fe}_{2} \mathrm{O}_{3}, \mathrm{~K} 2 \mathrm{O}, \mathrm{MgO}, \mathrm{MnO}_{2}, \mathrm{Na}_{2} \mathrm{O}, \mathrm{NiO}, \mathrm{P}_{2} \mathrm{O}_{5}, \mathrm{ZrO} \mathrm{Z}_{2}, \mathrm{ZnO}, \mathrm{TiO}_{2}$, $\mathrm{SrO}, \mathrm{Si}_{2}, \mathrm{SO}_{3}, \mathrm{PbO}$ with different percantage was used.

Population growth and urbanization increase waste water in our country as all over world; this increase also affects the number of waste water purification plants. The increase of plants cause to increase sewage sludge ash (SSA). SSA is stored, used as fill material. However in any method aside from burning problems occur in time. For this reason incineration of SSA is preferred in the leading European countries and other developed countries. By this way while the major source of environmental problem is eliminated both energy is produced and a harmless waste generated as ash. SSA contains above compound as oxide by not harmful to the environment. The annual amount of sewage is 3.5 billon $\mathrm{m}^{3}$ in Turkey[9]. When the 4 percentage of this amount is considered as waste sedimentary, 140 million tons SSA potential is available in Turkey. SSA incineration system was first developed in Gaziantep [10]. System generates electric by burning approximately 150 tons SSA per day. About 15 tons ash remains at the end of combustion. When the established mechanism is thought as a recycling system the use of remain ash increase the value of mechanism and also use of ash can be regarded as a versatile earning due to its environmental problem. Evaluation of the SSA in composite materials has been examined in the present study. For this purpose effect of sewage sludge ash on the mechanical proporties of composite material is aimed to seen. Tensile test, three point bending test, impact test are applied and their stress are calculated.

\section{Materials and Experimental Procedures}

The resin material used in composite manufacturing POLIPOL 3401 - TAB CTP type thixotropic accelerated general purpose polyester obtained from Poliya. Sewage sludge ash that was used as additive was provided from Gaziantep Metropolitan Municipality Water and Sewerage Department (GASKI). The compounds and their percantages in ash are showed at table 1 [11].

One of the most critical parameters is size of particle or fiber that affects mechanical proporties of composite materials, homogeneous distribution, adhesion and holding to resin/matrix [14, 15, 16, 17]. Provided ash sieved from 45 $\mu \mathrm{m}$ sieve. Short and small size fiber additives should be prefered due to it provides high specific surface area and uniform distribution of the composite $[14,16]$. Ash was sieved in order to achieve homogeneous distribution, good adhesion and provide a good uniformity between specimens which will be moulded and tested. Otherwise, if a composite specimen contains different size ashes, specimen will exhibit different strength behaviors due to the adhesion of ash. Hardener (MEKP) is 2 percentage of polyester weight for all specimens. The weight rate of ash is between $\% 0$ and $\% 45$. However 
for weight rate of $\% 45$ and above molding couldn't achive due to polyester - ash mixture become saturated so quickly. Materials and weight rate of them is at table 2. The tensile test sample referred as T, 3 - point bending test samples called as B, impact test samples called as I.

Table 1: Compound within ash and their percentage [11].

\begin{tabular}{|c|c|c|c|c|c|}
\hline Oxide & Percentage \% & Oxide & Percentage \% & Oxide & Percentage \% \\
\hline $\mathrm{P}_{2} \mathrm{O}_{5}$ & 23,655 & $\mathrm{~K}_{2} \mathrm{O}$ & 4,874 & $\mathrm{CuO}$ & 0,189 \\
\hline $\mathrm{CaO}$ & 19,588 & $\mathrm{ZnO}$ & 2,096 & $\mathrm{MnO}_{2}$ & 0,188 \\
\hline $\mathrm{SiO}_{2}$ & 16,602 & $\mathrm{TiO}_{2}$ & 1,079 & $\mathrm{NiO}$ & 0,068 \\
\hline $\mathrm{SO}_{3}$ & 8,533 & $\mathrm{Cl}$ & 0,539 & $\mathrm{Br}$ & 0,063 \\
\hline $\mathrm{MgO}$ & 8,221 & $\mathrm{Na}_{2} \mathrm{O}$ & 0,442 & $\mathrm{SrO}$ & 0,049 \\
\hline $\mathrm{Fe}_{2} \mathrm{O}_{3}$ & 7,461 & $\mathrm{Cr}_{2} \mathrm{O}_{3}$ & 0,354 & $\mathrm{ZrO}_{2}$ & 0,036 \\
\hline $\mathrm{Al}_{2} \mathrm{O}_{3}$ & 5,727 & $\mathrm{BaO}$ & 0,206 & $\mathrm{PbO}$ & 0,031 \\
\hline
\end{tabular}

For each class of samples (T0 - B0; T5 - B5; etc.) mixing and molding processes are performed simultaneously. Stirring has been made in laboratory with $1000 \mathrm{rev} / \mathrm{min}$ speed drills. Attention is paid to the homogeneity of the mixing apparatus fitted with a drill. By adding the particles and hardener to mixture the mixing process continued until mixture become gel form [3]. This form is extremely critical to avoid the negative factors, such as flocculation and precipitation may occur in the freezing process after casting the composite. Particles which are added polyester may be a factor increasing stress. These fillers can act as stress raisers that cause weakness in the structure by introducing discontinuity in stress transfer process across the filler-polymer interface [8]. These errors that will occur on the part is directly related with homogenity of composite during casting and freezing. The presence of agglomeration and voids in the composites obviously deteriorates their mechanical properties $[12,13]$.

Table 2: Weight Rate of Ingredient of Tensile Test and 3 Point Bending Test Specimens.

\begin{tabular}{|c|c|c|c|}
\hline Specimen & Polyester (\%) & Hardener (\%)* & Ash (\%) \\
\hline T0 - B0 - I0 & 98 & 2 & 0 \\
\hline T5 - B5 - I5 & 93 & 2 & 5 \\
\hline T10 - B10 - I10 & 88 & 2 & 10 \\
\hline T15 - B15 - I15 & 83 & 2 & 15 \\
\hline T20 - B20 - I20 & 78 & 2 & 20 \\
\hline T25 - B25 - I25 & 73 & 2 & 25 \\
\hline T30 - B30 - I30 & 68 & 2 & 30 \\
\hline T35 - B35 - I35 & 63 & 2 & 35 \\
\hline T40 - B40 - I40 & 58 & 2 & 40 \\
\hline
\end{tabular}

* The weight rate of hardener is $2 \%$ of weight of polyester.

Stirring is initiated by addition of the hardener by $\% 2$ weight of polyester. Ash was added to polyester - hardener before mixture become gel form. In this way, by hold on ash to mixture, it is intended to prevent the agglomeration and sedimentation. Each sample is keep at room conditions 3 weeks to ready for testing.

Figure 1 and figure 2 are the begining of polyester - hardener mixture and the reaction of polyester - hardener just before adding ash to mixture respectively. Discoloration of polyester resin is observed by reaction of hardener and polyester. The color of discoloration can vary according to kind of polyester. 


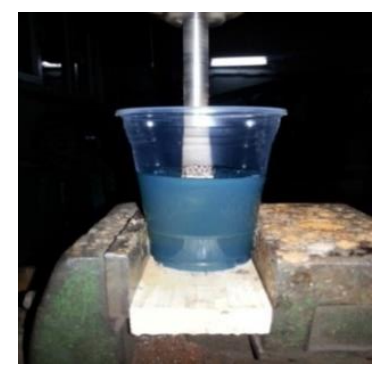

Fig. 1: Begining of Mixture.

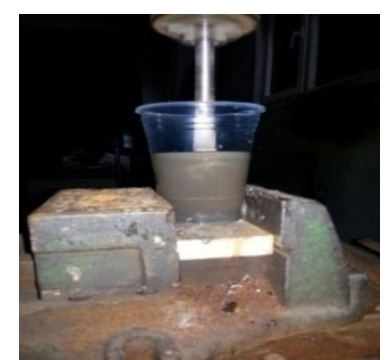

Fig. 2: Reaction of polyester and hardener.

\section{Mechanical Tests}

\subsection{Tensile Test}

Three samples are molded in order to apply tensile test accordance with standard ASTM D 3039. Samples are tested with a $300 \mathrm{kN}$ capacity universal test machine with $1 \mathrm{~mm} / \mathrm{sec}$ constant speed three weeks after casting. Our machine makes the measurement with 1 percentage sensitivity and gives datas by this sensitivity. Tensile strength is calculated again for each samples with final surface area after test is finished. Results are interpreted taking the average of three samples.

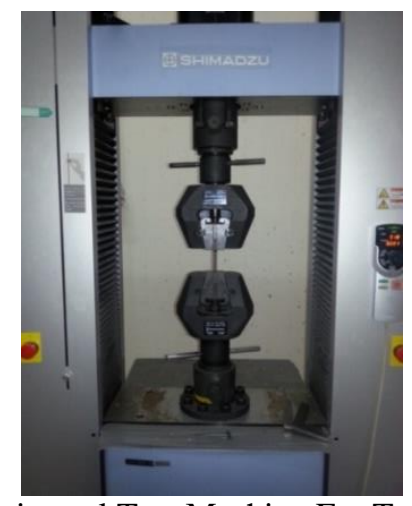

Fig. 3: Universal Test Machine For Tensile Test.

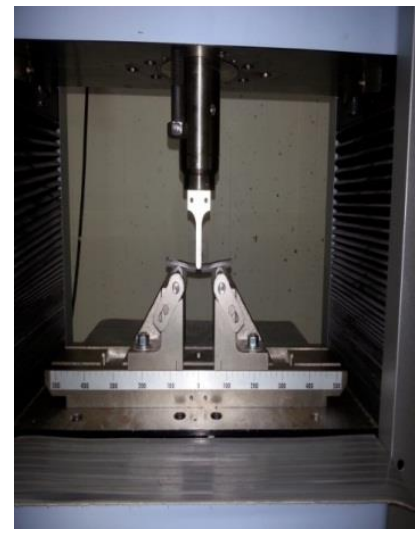

Fig. 5: Three Point Bending Test Machine.

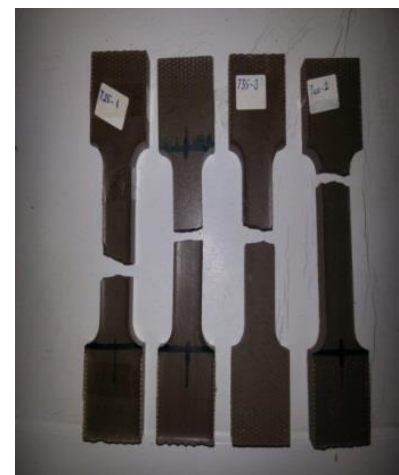

Fig. 4: Tensile Test Specimens.

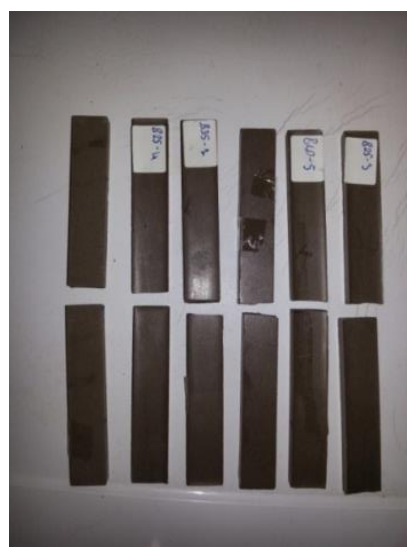

Fig. 6: Three Point Bending Test Samples.

\subsection{Three Point Bending Test}

In order to apply three point bending test three samples are molded into prepared mold. Samples are tested with a $300 \mathrm{kN}$ capacity universal test machine with $2 \mathrm{~mm} / \mathrm{sec}$ constant speed three weeks after casting. A large span to depth ratio in bending test increases the maximum normal stress without affecting the inter-laminar shear stress and thereby increases 
the tendency for longitudinal failure. If the span is short enough, failure initiates and propagates by inter-laminar shear failure. The maximum shear stress in a beam occurs at the mid-plane. So in the shear test, failure consists of a crack running along the mid-plane of the beam so that crack plane is parallel to the longitudinal plane [4]. In the present investigation, during flexural test, the span length is 16:1. Results are interpreted taking the average of three samples.

$$
\begin{gathered}
\tau_{m}=\frac{|M|}{S} \\
S=\frac{1}{6} b h^{2}
\end{gathered}
$$

where $\tau_{m}$ is bending stress, $M$ is bending moment, $b$ is width of the cross section, $\mathrm{h}$ is depth of the cross section.

\subsection{Impact Test}

There are several mechanisms for toughening of polymer. For the inorganic particles toughening polymer, at least three factors are necessary: inherent ductility of the matrix, weak interphase supporting the filler/matrix debonding and suitable interparticle distance. The stress concentration first leads to debonding of the filler particles and voids formation. The particle content affects the interparticle distance and the stress state of the matrix polymer surrounding the voids [18]. Load is carried by the material during the impact test is an important parameter for the material that can be related to fracture or damage.

Impact test represents the energy needed to break the sample.This magnitude is called as failure energy ad denoted with W;

$$
K=\frac{W}{A}
$$

$K=$ Impact Resistance: $\left(J / m^{2}\right), \quad W=$ Failure energy: $J$,

$A=$ the area of the specimen cross-section where fracture occurs: $m^{2}$

Impact strength was calculated again for each samples with last surface area after test finished. Results were interpreted taking the average of five samples. The dimension of impact test specimen is $55 * 10 * 10$.

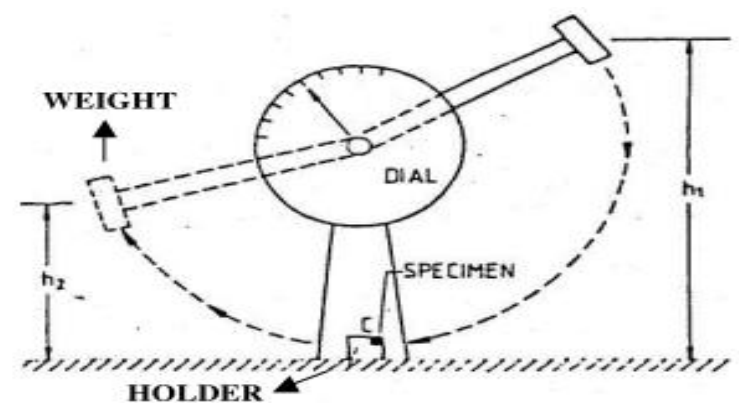

Fig. 7: The Schematic Designation of Impact Test Machine.

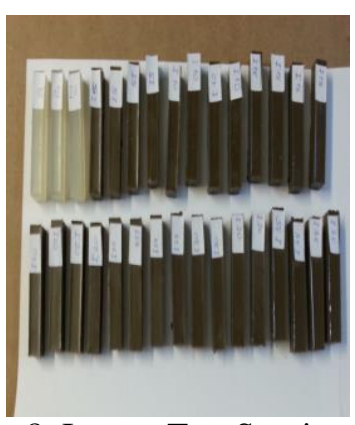

Fig. 8: Impact Test Specimens.

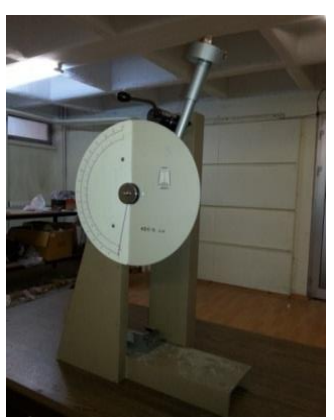

Fig. 9: Impact Test Machine. 


\section{Results}

For each sample of tensile test, three point bending test and impact test, new calculations are made for stress after tests are finished with final surface area where fracture occur due to the shrinking characteristics of polyester resin.

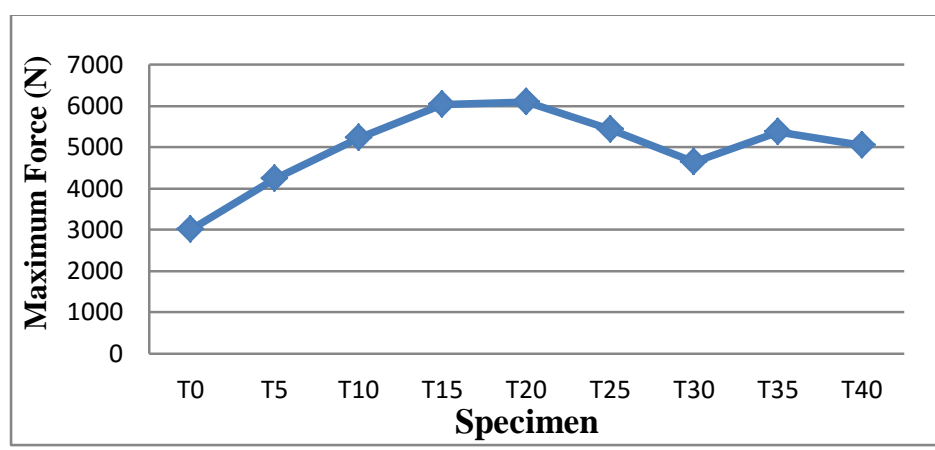

Fig. 10: Max. Force - Specimen Diagram for Tensile Test.

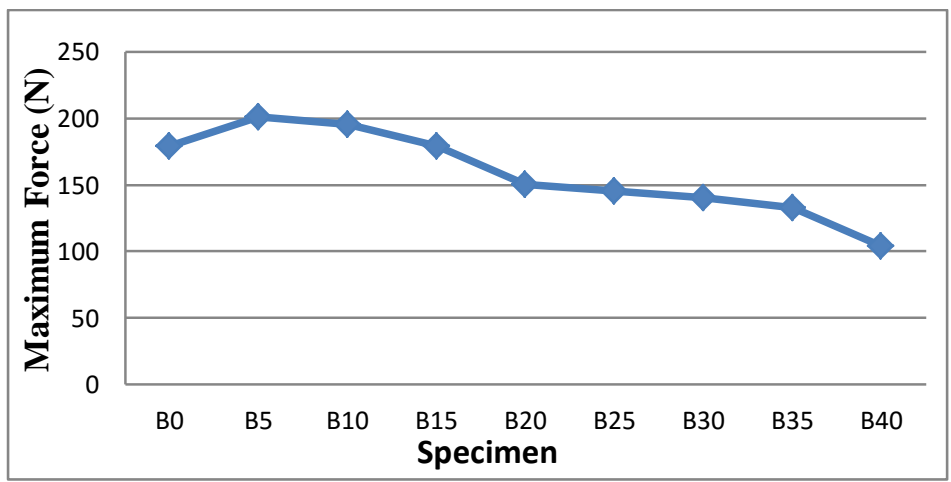

Fig. 12: Max. Force-Specimen Diagram for 3 Point Bending Test.

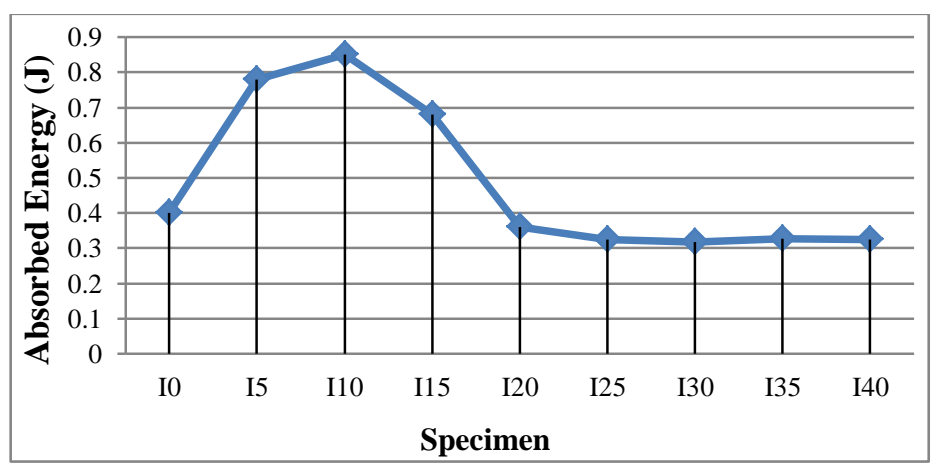

Fig. 14: Impact Test, Absorbed Energy (J) - Specimen Diagram.

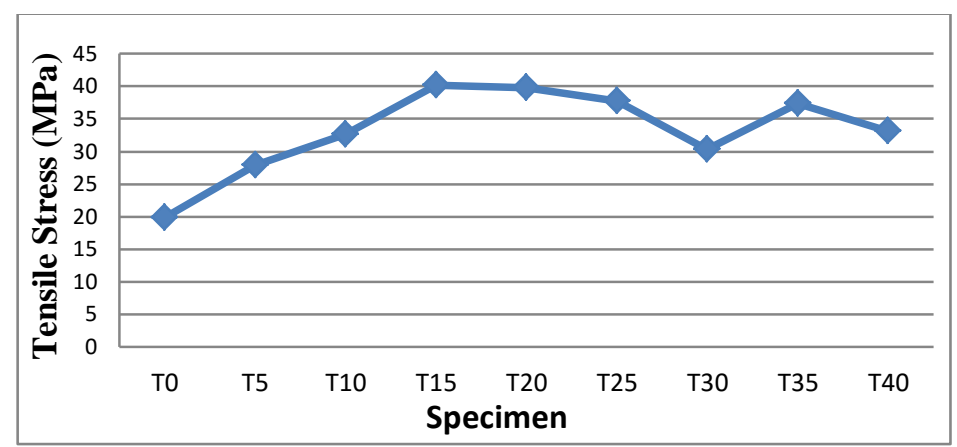

Fig. 11: Tensile Stress - Specimen Diagram for Tensile Test.

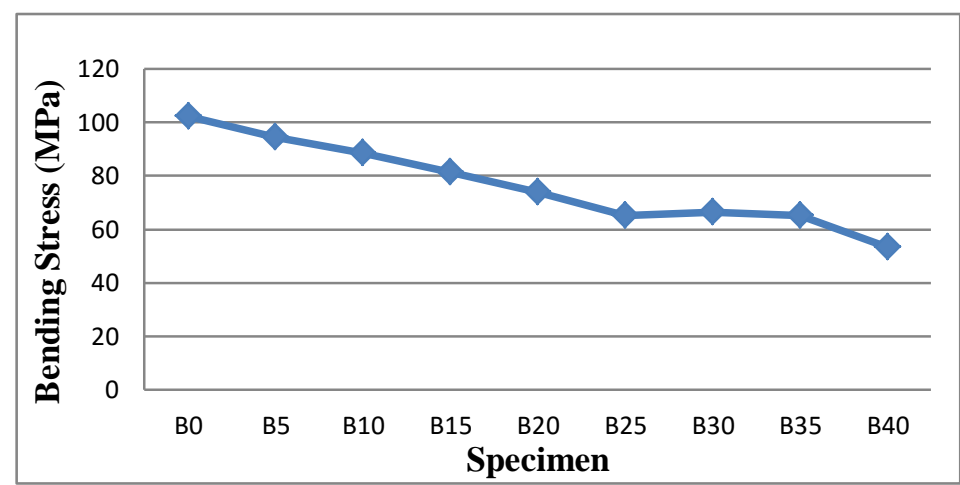

Fig. 13: Stress - Specimen Diagram for 3 Point Bending Test.

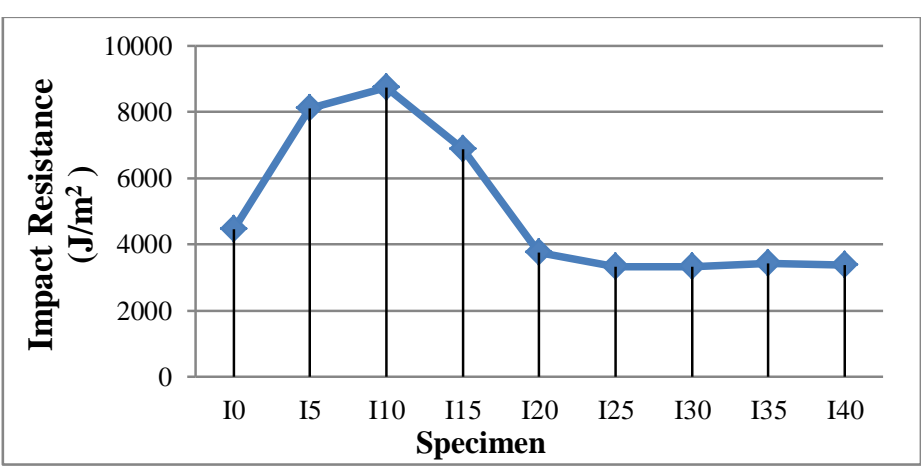

Fig. 15: Impact Test,Impact Resistance $\left(\mathrm{J} / \mathrm{m}^{2}\right)$-Specimen Diagram.

As shown from figure 10 and 11, maximum force that occurs at fracture and associate with tensile stress increase until weight rate of ash reach $20 \%$ of total mixture (polyester - hardener - ash). It can be interpreted that homogenity (distrubution of ash in the mixture) is good, adhesion and interaction of resin and ash is good. Maximum force and tensile strength decrease from $\% 20$. This decline is unexpected at \% 30. Stirring is one of the most critical point in the production of composite materials as previously discussed. A homogeneous mixture may not be made for $\% 30$. Another factor may be voids in the material can not be visible. These voids would cause stress concentration which may lead to sudden rupture. Another reason for sudden rupture may be adhesion between polyester resin and ash is not good. It could be a significant effect for the sudden drop for weight rate of $\% 20$ and up; increase the weight rate of ash content in the composite material means that the reduction of the distance between particles. This causes irregularity and stress concentration. As a result, maximum force and associated with tensile stress decrease. 
As seen at graphic 12 and graphic 13, according to result of three point bending test as the weight rate of ash content in the composite increase, the strength values decrease. This decrease is very close between rate of $\% 20$ and $\% 35$,in fact it showed a constant charecter.At $\% 40$ the strength value decrease again.Actually for weight rate of $5 \%$ the maximum force showed a increase tendency.However this inrease was eliminated by new cross section area where fracture occur.

As seen from figures 14 and 15, impact resistance and absorbed energy increase until weight rate of ash reaches $10 \%$. They decrease between $10 \%$ and $20 \%$. After from $20 \%$ impact resistance and absorbed energy showed nearly constant value.

Table 3: Impact Test Results.

Table 4: Three Point Bending Test Results.

\begin{tabular}{|c|c|c|c|}
\hline Test Type & Specimen & $\begin{array}{c}\text { Absorbed } \\
\text { Energy(J) }\end{array}$ & $\begin{array}{c}\text { Impact } \\
\text { Resistance(J/m2) }\end{array}$ \\
\hline \multirow{4}{*}{ Impact } & $\mathrm{I} 0$ & 0,4 & 4458,38 \\
\cline { 2 - 4 } & $\mathrm{I} 5$ & 0,78 & 8100,86 \\
\cline { 2 - 4 } & $\mathrm{I} 10$ & 0,85 & 8746,29 \\
\cline { 2 - 4 } & $\mathrm{I} 15$ & 0,68 & 6880,32 \\
\cline { 2 - 4 } & $\mathrm{I} 20$ & 0,36 & 3751,5 \\
\cline { 2 - 4 } & $\mathrm{I} 25$ & 0,325 & 3319,28 \\
\cline { 2 - 4 } & $\mathrm{I} 30$ & 0,3175 & 3319,57 \\
\cline { 2 - 4 } & $\mathrm{I} 35$ & 0,327 & 3435,17 \\
\cline { 2 - 4 } & $\mathrm{I} 40$ & 0,325 & 3362,62 \\
\hline
\end{tabular}

\begin{tabular}{|c|c|c|c|c|}
\hline Test Type & Specimen & $\begin{array}{c}\text { Maximum } \\
\text { Force (N) }\end{array}$ & $\begin{array}{c}\text { Strength } \\
\text { (Mpa) }\end{array}$ & $\begin{array}{c}\text { Maximum } \\
\text { Strain (\%) }\end{array}$ \\
\hline \multirow{4}{*}{$\begin{array}{c}\text { Three Point } \\
\text { Bending } \\
\text { Test }\end{array}$} & B0 & 179,29 & 102,39 & 5,08 \\
\cline { 2 - 5 } & B5 & 200,94 & 94,50 & 3,65 \\
\cline { 2 - 5 } & B10 & 195,22 & 88,57 & 2,83 \\
\cline { 2 - 5 } & B15 & 179,05 & 81,23 & 2,78 \\
\cline { 2 - 5 } & B20 & 150,49 & 74,03 & 2,6 \\
\cline { 2 - 5 } & B25 & 145,10 & 65,31 & 1,76 \\
\cline { 2 - 5 } & B30 & 140,09 & 66,42 & 1,85 \\
\cline { 2 - 5 } & B35 & 132,56 & 65,21 & 1,72 \\
\cline { 2 - 5 } & B40 & 103,81 & 53,47 & 1,22 \\
\hline
\end{tabular}

Table 5: Tensile Test Results.

\begin{tabular}{|c|c|c|c|c|}
\hline Test Type & Specimen & $\begin{array}{c}\text { Maximum } \\
\text { Force (N) }\end{array}$ & $\begin{array}{c}\text { Strength } \\
\text { (Mpa) }\end{array}$ & $\begin{array}{c}\text { Maximum } \\
\text { Strain(\%) }\end{array}$ \\
\hline \multirow{4}{*}{$\begin{array}{c}\text { Tensile } \\
\text { Test }\end{array}$} & $\mathrm{T} 0$ & 3003,79 & 19,76 & 1,78 \\
\cline { 2 - 5 } & $\mathrm{T} 5$ & 4245,85 & 27,93 & 2,58 \\
\cline { 2 - 5 } & $\mathrm{T} 10$ & 5225,13 & 32,66 & 3,8 \\
\cline { 2 - 5 } & $\mathrm{T} 15$ & 6036,38 & 40,14 & 4,11 \\
\cline { 2 - 5 } & $\mathrm{T} 20$ & 6108,76 & 39,77 & 4,8 \\
\cline { 2 - 5 } & $\mathrm{T} 25$ & 5429,17 & 37,70 & 4,08 \\
\cline { 2 - 5 } & $\mathrm{T} 30$ & 4649,83 & 30,27 & 1,78 \\
\cline { 2 - 5 } & $\mathrm{T} 35$ & 5380,82 & 37,37 & 2,72 \\
\cline { 2 - 5 } & $\mathrm{T} 40$ & 5038,88 & 33,15 & 2,05 \\
\hline
\end{tabular}

\section{Conclusion and Discussion}

In the current study a research on effect of sewage sludge ash on the mechanical properties of composite material is carried out. Tensile test, three point bending test and impact test are handed as mechanical tests. Polyester is used as resin material during the preparation of mixture. In the first step of study, the homogenous of mixture must be achieved in order to take faultless results. If not, results show a wavy character. This is achieved by adding correct weight ratio of hardener at correct time. That is sedimentation is prevented by adding hardener at true time.

Test results showed that adding sewage sludge ash to polyester affect the mechanical properties of composite significantly. For tensile test result, tensile stress increase until weight rate of ash reach $20 \%$ and beyond it decreases. For three points bending test, adding of sewage sludge ash affects negatively to composite. In other words adding ash decreases the bending stress of material. Finally for impact test, absorbed energy and impact resistance increase until adding ash reaches $10 \%$ and beyond it decreases.

By current study, sewage sludge ash which has not been used before is used and tested in the literature for the first time. This is not the single point for importance of study. As mentioned before this kind of ash is a waste of the combustion process. Sewage sludge ash is not useful yet for any industry and is useless waste, generally disposed as landfill. If the use of ash is achieved an environmental problem will be overcome. 


\section{References}

[1] A. C. Cerbu, H. Teodorescu and L. Scutaru, "Adding Fillers to Change the Mechanical Behaviour of the Glass Composite Materials," in Proceedings of the World Congress on Engineering, vol. 3, WCE 2011, London, U.K, 2011.

[2] B. Pukanszky, "Particulate Filled Polypropylene: Structure and Properties," in Polypropylene: Structure, Blends and Composites, J. Karger-Kocsis, Ed. London: Chapman \& Hall, pp. 1-70.

[3] K. C. Jajam, H. V. Tippur, “A study of nano- vs. micro-size ifller and loadin $\square$ rate effects,” Part B, vol.43, pp. 34673481, 2012.

[4] A.Patnaik, A. Satapathy, S. S. Mahapatra and R. R. Dash, "A Comparative Study on Different Ceramic Fillers Affecting Mechanical Properties of Glass-Polyester Composites," Journal of Reinforced Plastics and Composites, vol. 28, no. 11, pp. 1305-1318, 2009.

[5] B. R. Raju, B. Suresha, R. P. Swamy and B. S. G. Kanthraju, "Investigations on Mechanical and Tribological Behaviour of Particulate Filled Glass Fabric Reinforced Epoxy Composites," Journal of Minerals and Materials Characterization and Engineering, vol. 1, pp. 160-167, 2013.

[6] M. Rusu, N. Soifa $\square$ and D. Rusu, "Mechanical and thermal properties of zinc powder iflled high density polyethylen $\square$ composites, $\square$ Polymer Testing, vol. 20, pp. 409-417, 2001.

[7] A. Gungor, "Mechanical properties of iron powder iflled high density polyethylene composites, $\square$ ScienceDirect: Materials \& Design, vol. 28, pp. 1027-1030, 2007.

[8] M.S. Bhagyashekar, R.M.V.G.K. Rao, "Characterization of Mechanical Behavior of Metallic and Non-metalic Particulate Filled Epoxy Matrix Composites," Journal of Reinforced Plastics and Composites, vol. 29, no. 30, 2010.

[9] TUIK, "Municipals Waste Water Statistics," Turkish Statistical Institute, 2010.

[10] M. A. Kütük and M. Aksoy, "A Case Study On Sewage Sludge Incineration Plant: GASKI," in Proceedings of the Second International Conference on Water, Energy and the Environment Kusadasi, Turkey, 2013.

[11] "Türkiye Bilimsel ve Teknolojik Araştırma Kurumu," Marmara Araştırma Merkezi: Çevre Enstitüsü, 2049 Nolu Analiz Raporu, 2010.

[12] M. Hussain, Y. Oku, A. Nakahira, and K. Niihara, "Effects of Wet Ball-milling on Particle Dispersion and Mechanical Properties of Particulate Epoxy Composites," Materials Letters, vol. 26, pp. 177-184, 1996.

[13] B. Wetzel, F. Haupert, and M. Q. Zhang, "Epoxy Nanocomposites with High Mechanical and Tribological Performance," Composites Science and Technology, vol. 63, pp. 2055-2067, 2003.

[14] A. Nourbakhsh, A. Karegarfard, A. Ashori and A. Nourbakhsh, "Effects of Particle Size and Coupling Agent Concentration on Mechanical Properties of Particulate-filled Polymer Composites," Journal of Thermoplastic Composite Materials, vol. 23, no. 2, pp. 169-174, 2010.

[15] S. Y. Fu , X. Q. Feng, B. Lauke and Y. W. Mai, "Effects of particle size, particle/matrix interface adhesion and particle loading on mechanical properties of particulate-polymer composites," ScienceDirect: Composites - Part B, vol. 39, pp. 933-961, 2008.

[16] W.S. DePolo and D. G. Baird, "Particulate Reinforced PC/PBT Composites. I. Effect of Particle Size (Nanotalc Versus Fine Talc Particles) on Dimensional Stability and Properties," vol. 30, no. 2, pp. 188-199, 2009.

[17] L. Yusriah, M. Mariatti and A. A. Bakar, "Mechanical Properties of Particulate-Filler/Woven-Glass-Fabric-Filled Vinyl Ester Composites," Journal of vinyl \& Additive technology, vol. 16, no. 1, pp. 98-104, 2010.

[18] S. Zhang, X. Y. Cao, Y. M. Ma, Y. C. Ke, J. K. Zhang and F. S. Wang, "The effects of particle size and content on the thermal conductivity and mechanical properties of Al2O3/high density polyethylene (HDPE) composites," eXPRESS Polymer Letters, vol.5, no.7, pp. 581-590, 2011.

[19] S. Donatello and C. R. Cheeseman, "Recycling and recovery routes for incinerated sewage sludge ash (ISSA): A review," Waste Management, vol. 33, pp. 2328-2340, 2013.

[20] M. Smol, J. Kulczycka, A. Henclik, K. Gorazda and Z. Wzorek, "The possible use of sewage sludge ash (SSA) in the construction industry as a way towards a circular economy," Journal of Cleaner Production, vol 95, pp. 45-54, 2015.

[21] C. J. Lynn, R. K. Dhir, G. S. Ghataora and R. P. West, "Sewage sludge ash characteristics and potential for use in concrete," Construction and Building Materials, vol. 98, pp. 767-779, 2015. 